\title{
会计电算化对会计工作方法的影响研究
}

\author{
李中兴 \\ 长治市辛安泉域管理中心 \\ DOI:10.32629/ej.v2i6.314
}

[摘 要] 现代社会飞快进步和发展下,现代化信息技术以其独特的优势广泛应用到各个行业领域,为新时期会计领域高维度发展指明了新的 方向。在现代化信息技术和网络技术支持下,会计电算化成为会计行业革新的主要趋势,有助于降低人工劳动强度,从繁忙工作负担中脱离出 来,提升会计人员工作效率和质量。本文就会计电算化对会计工作方法的影响进行分析,把握会计电算化内涵,提出合理措施来推动会计工作 改革深化。

[关键词] 会计方法; 会计电算化; 会计凭证; 内部管理

社会主义市场经济持续增长下, 企业的现代化管理水平逐步提升, 制 定了相应的制度和标准, 提升企业管理水平的同时, 为企业管理和决策提 供可靠依据。在企业内部财务管理中, 实行会计电算化, 推动传统会计工作 创新, 转变理念, 优化会计管理方式, 有助于复杂的会计工作精简化, 提升 工作效率的同时, 培养更多高素质的会计人才。通过分析会计电算化对会 计工作方法的影响, 不断推动会计工作方法创新, 指导后续企业会计工作 展开。

\section{1 会计电算化的内涵}

会计电算化是传统会计革新的主要趋势, 顺应信息时代带来的挑战和 要求, 依托于信息技术和计算机技术, 构建应用平台, 可以实现数据高效加 工和处理, 提升会计工作现代化水平。在会计电算化的广泛推广和应用下, 会计工作方法发生了不同程度的变化, 有助于降低人工劳动强度, 提升会 计工作效率, 为企业管理和决策提供可靠会计数据同时, 推动会计行业更 高层次发展 ${ }^{[1]}$ 。

\section{2 会计电算化对会计工作方法的影响}

2. 1会计工作理念发生转变

会计电算化的应用, 致使会计工作理念发生了不同程度的变化, 可以 有效提升会计工作效率。以往的手工记账和业务处理方法局限性较大, 伴 随着一系列的数据风险, 与现代企业经营管理要求相背离 ${ }^{[2]}$ 。会计电算化 应用发展下, 会计人员需要转变理念, 养成竞争意识和市场意识, 促使会计 工作从被动转变为主动。在会计电算化背景下, 使用计算机和会计软件, 通过电子化记账和转账, 自动化分析和处理会计信息, 降低人员的财务工 作压力, 减少认为主观意识带来的偏差, 切实提升会计工作效率和质量。

2. 2 推动企业审计内容转变

会计电算化在企业的广泛应用下, 会计工作流程和工作方法不断优化 创新, 配套的企业审计内容随之转变。通过对传统会计工作方式分析, 检查 原始会计凭证和财务报表数据是否真实可靠, 工作量较大。而实行会计电 算化, 通过信息技术和计算机技术, 可以摒弃传统手工记账中的风险, 重点 对会计核算软件合理性进行审计, 同时需要定期更新和维护会计核算软件, 保证会计工作效率和质量。

\section{3优化会计人员专业能力}

积极推动会计电算化应用, 依托于现代化信息技术来改进传统会计工 作不足, 不断提升会计人员专业能力。会计电算化对会计人员的专业能力 要求较高, 需要熟练运用计算机技术和现代化信息技术, 满足会计电算化 要求。同时, 会计电算化对企业的内部管理影响较大, 将会计部门职责进一 步细化, 促使会计人员积极参与到企业管理和决策中, 提升企业的会计核 算水平 ${ }^{[3]}$ 。

\section{4 促进会计职能转变}

推动会计电算化的有效应用, 改善传统会计工作方法的不足同时, 推 动会计岗位职能转变。经济管理模式的优化重构, 赋予会计岗位新的特点, 具有会计职能核算、职能分析和审计监督职能, 为新时期的会计工作指明 了新的方向。积极推动信息技术、计算机技术应用,构建一体化的电算系 统, 实现会计信息预测和分析, 会计核算效率提升的同时, 辅助管理和决 策。当前网络时代背景下, 会计电算化呈现良好发展前景, 降低会计核算人 力成本损耗, 将成本控制在合理范围内, 推动会计工作规范化发展。

\section{3 企业会计电算化的应用途径}

纵观当前企业会计电算化现状来看, 尽管会计电算化的应用可以推动 会计工作方法改进创新, 提升会计核算水平, 但是其中仍然存在一系列问 题, 会计电算化软件开发力度不足, 缺乏统一标准和高素质人才, 极大的制 约企业现代化发展。故此, 针对其中的问题, 应提出切实可行的措施推动会 计电算化应用。

3. 1 提升会计人员对会计电算化认知

以往企业的财会工作中, 缺乏统一的标准和规定, 市场上不同企业的 财务软件有所差异, 会计监督难度较大。当前我国会计电算化发展速度较 快, 但是由于缺乏统一的标准, 致使会计软件算法存在差异, 影响到不同企 业之间的协作和交流 ${ }^{[4]}$ 。故此, 在企业会计核算中应用会计电算化, 需要会 计人员转变理念, 加深对会计电算化的认知和重视, 可以熟练运用会计电 算化进行会计核算。树立管理思维, 提升会计电算化的应用意识和风险意 识, 分析潜在的风险要素, 定期检查会计软件的漏洞和风险, 及时将会计档 案备份管理, 推动会计电算化发展。与此同时, 迎合新时期发展要求, 运用 信息技术和计算机技术, 充分发挥会计电算化性能, 及时消除潜在的风险 隐患, 提升会计核算效率和质量。

3. 2 加强会计软件系统开发和创新

为了推动企业现代化发展, 应不断改进和完善企业管理制度, 摸索市 场经济发展规律, 推动手工记账朝着会计电算化发展 ${ }^{\left[{ }^{[5]}\right.}$ 。但是, 我国会计软 件质量良莠不齐, 其中有一定的漏洞和风险, 极大的影响到企业财务数据 信息真实性和安全性。部分企业的会计核算软件功能单一, 各部门之间协 调补偿, 都可能影响到会计信息共建共享。故此, 积极推动会计电算化软件 创新, 丰富会计软件功能, 实现各部门的信息共建共享, 提升部门协同效 果。通过SAP软件, 加强各部门联系, 深入挖掘和利用会计信息。需要注意 的是, 会计软件的开发, 应充分企业不同企业的类型需要, 提升会计软件协 同性和广泛性。开发具有审计功能的会计软件, 提升企业会计核算水平, 并通过会计软件的审计功能, 提升会计审计水平。

3. 3培养高素质的会计人才 


\title{
关于事业单位档案管理工作创新的探讨
}

\author{
闵丽娜 \\ 洮南市劳动保障事务所
}

DOI:10.32629/ej.v2i6.268

[摘 要] 事业单位是政府相关政策的具体落实机构,事业单位的整体管理质量直接影响着政府一系列政策的具体落实情况,因此事业单位在新 时期更应做好自身管理工作为我国现代化社会建设发挥自身应有作用。事业单位档案管理工作是其整体管理工作的重要组成部分,事业单位档 案对于其自身发展以及工作质量来讲有重要意义,其不仅起到了全面记录相关工作资料的作用,同时也能在单位未来发展上起到良好的指导作 用。当前我国事业单位自身档案管理工作仍存在一系列的问题,如果我们不能针对这些问题提出相应的创新内容来有效提升整体档案管理工作 质量那么事业单位的未来发展将会受到严重影响。

[关键词] 事业单位; 档案管理; 问题; 创新思考

随着我国社会的不断发展进步, 事业单位在社会建设中扮演的角色也 越来越重要, 为了满足新时期社会建设发展需求, 各事业单位都在不断针 对自身工作需求来对自身各个管理内容进行积极的创新研究, 这是为了有 效改善当前事业单位管理工作中存在的各种问题。事业单位档案管理工作 是其管理工作的重要组成部分, 能否科学妥善的完成事业单位档案管理工 作直接影响到了事业单位的未来发展, 档案管理工作对于事业单位来讲是 将各类工作资料、人事资料等各种重要信息进行搜集、整理、储存、调取、 利用的重要管理工作, 随着现代化档案管理理念以及档案管理技术的不断 发展, 事业单位在工作中应用的传统档案管理理念及管理技术已经不能满 足当前工作需求, 为了进一步优化事业单位档案管理工作的工作质量同时 最大程度发挥档案资料的自身价值, 我们必须明确当前档案管理工作中我 们存在的相应问题, 并且针对各项问题进行创新思考。

\section{1 当前事业单位档案管理工作存在的问题}

1. 1对档案管理工作的重视程度偏低

随着我国社会的现代化建设不断加快, 事业单位作为政府政策的主要 落实执行部门在现代化社会建设中承担的责任也越来越多, 而事业单位的 工作质量以及工作效率自然要从政策落实情况上来进行分析, 因此绝大多 数事业单位在日常工作中都更加重视实际工作执行情况, 在主要工作方向 上极大地强化工作人员的专业素质并且要求其达到相应的工作效率, 但是 在这样的管理推进内容中却较少有人注意到事业单位档案管理工作的重 要性, 在事业单位管理工作的发展中, 档案管理工作的发展情况相较其它 管理内容有较大的落差, 这首先是由于领导对档案管理工作的重视程度不

如何更加充分的发挥会计电算化优势, 应充分契合企业的实际发展需 要, 积极加强会计人员培养 ${ }^{[6]}$ 。构建会计人才培养基地, 增加资金投入力度, 引导会计人员加深会计电算化认知和了解, 夯实专业知识储备的同时, 具 备更强的现代化信息技术应用能力, 养成良好的职业素养, 为企业的会计 电算化应用提供坚实保障。需要注意的是, 企业应定期组织会计人员参加 专业培训和考核, 学习会计电算化运用方法, 提升实践能力的同时, 对财务 数据深入法预测和分析, 以便于全面提升企业的会计水平。

\section{4 结束语}

综上所述, 推动企业会计电算化的应用, 是企业顺应激烈市场竞争的 必然选择, 同时也是企业现代化管理改革的重要内容。顺应时代发展趋势, 推动会计工作方法创新改进, 夯实理论基础的同时, 灵活运用现代化技术, 充分发挥会计电算化优势, 提升会计核算水平, 推动企业健康持续发展意 义深远。
足, 没有深入了解档案管理工作对于日常工作质量、工作效率以及单位未 来发展中所具有的重要指导作用, 大多数工作人员对于本单位档案的理解 仅仅只是一种需要被保管的资料而已, 他们没有意识到事业单位档案具有 极强的历史见证意义, 对于档案自身价值的发掘工作更是持漠视的态度, 这就导致了事业单位档案管理工作长时间保持旧有工作模式, 而新时代下 传统档案管理理念及管理技术早就不能满足现代化档案管理需求, 档案管 理工作的现代化发展成果令人非常堪忧 ${ }^{[1]}$ 。

\section{2 事业单位档案管理技术落后}

随着我国档案管理技术的不断发展, 数字化档案管理模式已经普遍应 用于各种档案管理工作之中, 然而, 由于事业单位档案管理工作自身受重 视程度相对较低, 这就导致了档案管理技术相对比较落后, 虽然多数事业 单位档案管理部门也逐渐开始应用数字化档案管理系统对自身涉及到的 档案进行相应的管理工作, 但是其应用深度以及硬件条件等还存在很大的 差异, 现代化档案管理的建设工作既需要硬件支持同时也需要相应的软件 系统配合, 而且在实际工作运行过程中不同单位对于数字化档案管理技术 的应用程度有很大差异, 很多单位虽然具备相应的技术条件但是在实际工 作运行过程中依旧遵循传统档案管理目标, 仅仅是将纸质档案文件转化为 数字资料形式进行存储, 数字化档案管理技术的优势没有充分体现。更严 重的是很多单位至今也没能完成传统档案管理技术向数字化档案管理的 迈进, 很多档案资料没有完成数字化转换, 甚至连当前新产生的档案也没 有充分进行数字化处理, 种种情况一方面由于数字化档案管理建设不到位, 硬件条件不允许, 一方面也与档案管理规模以及档案管理目标有关 ${ }^{[2]}$ 。

\section{[参考文献]}

[1]徐林伟.地方国有企业会计电算化向会计信息化集成应用[J].中国 农业会计,2019,12(08):26-28.

[2]阎素玉.山西企业会计电算化与共享价值评价体系的构建[J].财会 学习,2019,22(27): 140-141.

[3]张强,王晶.化工企业会计电算化存在的问题及解决措施[J].金融经 济,2019,31(18):221-222.

[4]聂建勇.事业单位会计电算化应用中存在的问题及解决措施[J].中 小企业管理与科技(中旬刊),2019,6(09):83-84.

[5]张战友.会计电算化课程对学生实践能力培养的有效途径研究 [J]. 中外企业家,2019,29(25):211-212.

[6]侯超.会计电算化模式下审计工作存在的问题和对策研究 [J].中国 管理信息化,2019,22(17):43-44. 